\title{
An aldose redutase inhibitor prevents the intimal thickening in coronary arteries of galactose-fed beagle dogs
}

\author{
Y. Kasuya ${ }^{1}$, M. Ito ${ }^{2}$, J. Nakamura ${ }^{1}$, Y. Hamada ${ }^{1}$, M. Nakayama ${ }^{1}$, S. Chaya ${ }^{1}$, T. Komori ${ }^{1}$, K. Naruse ${ }^{1}$, E. Nakashima ${ }^{1}$, \\ K. Kato ${ }^{1}$, N. Koh ${ }^{1}$, N. Hotta ${ }^{1}$ \\ ${ }^{1}$ The Third Department of Internal Medicine, Nagoya University School of Medicine, Nagoya, Japan \\ ${ }^{2}$ Department of Pathology Nagoya University Hospital, Nagoya, Japan
}

\begin{abstract}
Aims/hypothesis. Although increased polyol pathway activity has been implicated in the pathogenesis of diabetic microangiopathy, the relation with diabetic macroangiopathy remains unclear. Galactose feeding is known to stimulate the polyol pathway and to develop abnormalites similar to those in diabetic microangiopathy. Our study was conducted to investigate whether an activation of polyol pathway by long-term treatment with galactose produced morphological changes in coronary arteries of dogs and the effect of an aldose reductase inhibitor, epalrestat, was also studied.

Methods. Dogs received either normal chow or chow containing $30 \%$ galactose with or without epalrestat given orally $\left(20\right.$ or $\left.50 \mathrm{mg} \cdot \mathrm{kg}^{-1}\right)$. After 44 months, morphometric analyses of coronary arteries were carried out and the galactitol contents in aortas were measured.
\end{abstract}

Results. The ratio of areas of the intimal layer to those of the medial layer, an indicator of intimal thickening, was statistically significantly increased in galactosefed dogs compared with control dogs. Galactose-fed dogs had a remarkable accumulation of galactitol in their aortas. These morphological and biochemical deficits were reduced by treatment with epalrestat.

Conclusion/interpretation. This report morphologically shows diabetes-like macrovascular abnormalities in galactosaemic animals, suggesting that polyol pathway hyperactivity is closely related to the development of diabetic macroangiopathy, which could be prevented by aldose reductase inhibition. [Diabetologia (1999) 42: 1404-1409]

Keywords Aldose reductase inhibitor, polyol pathway, diabetic macroangiopathy, galactose.
Macrovascular complications such as myocardial infarction, angina pectoris and cerebrovascular accidents are the major causes of mortality in diabetic patients $[1,2]$. Although the maintenance of a good glycaemic control for a long period can decrease the risk of the development of diabetic microangiopathy [3], the development of diabetic macroangiopathy cannot

Received: 7 June 1999 and in revised form: 6 August 1999

Corresponding author: J. Nakamura, MD, The Third Department of Internal Medicine, Nagoya University School of Medicine, 65 Tsuruma-cho, Showa-ku, Nagoya 466-8550, Japan Abbreviations: PKC, Protein kinase C; DAG, diacylglycerol; IA, intimal area; MA, medial area. be prevented by glycaemic control [3,4]. Therefore, it is very important to establish the pathogenesis of diabetic macroangiopathy.

Various hypotheses including increased polyol pathway activity, protein kinase C (PKC) activation, increased oxidative stress and enhanced non-enzymatic glycation have been implicated in the pathogenesis of diabetic microangiopathy such as retinopathy, nephropathy and neuropathy [5, 6]. Hyperglycaemia-induced metabolic alterations could also contribute to the development of diabetic macroangiopathy. Although the importance of the latter three metabolic deficits in the pathogenesis of diabetic macroangiopathy have been investigated precisely [7-12], the relation between polyol pathway hyperactivity and diabetic macroangiopathy remains unclear. 
As the rate-limiting enzyme of the polyol pathway, aldose reductase, can convert galactose to galactitol, which is only poorly metabolized by sorbitol dehydrogenase [13]. Galactose-feeding provides an enhanced flux through the first step of the polyol pathway and does not cause either hyperglycaemia, hypo-insulinaemia, hyperinsulinaemia or hyperlipidemia. Therefore, the galactosaemic animal is a suitable model for studying the effects of polyol pathway hyperactivity itself. The galactose model should also help to avoid problems resulting from the limited life-span of experimental animals and increased mortality associated with long-standing diabetes. Previous studies have shown functional, biochemical or morphological abnormalities in galactosaemic animals similar to those in diabetic neuropathy, retinopathy or nephropathy [14-20]. In addition, functional or biochemical deficits in galactosaemic rat aorta or aortic smooth muscle cells cultured with increased galactose concentrations $[8,21]$ suggest that galactose feeding could also cause diabetes-like macroangiopathy. Morphological analyses of galactose-induced macroangiopathy have, however, never been reported.

Our study was conducted to investigate whether activation of the polyol pathway by long-term treatment with galactose produced morphological changes in coronary arteries and the effect of an aldose reductase inhibitor, epalrestat [E-3-carboxymethyl-5(2E-methyl-3-phenylpropenylidene) rhodamine] [22, 23], was also studied.

\section{Materials and methods}

Animals. Healthy male beagle dogs (CSK Research Park, Nagano, Japan) aged 5 months were housed in separate cages and divided at random into four groups as follows: (1) control dogs, (2) galactose-fed dogs, (3) galactose-fed and low dose epalrestat $\left(20 \mathrm{mg} \cdot \mathrm{kg}^{-1} \cdot \mathrm{day}^{-1}\right)$-treated dogs, (4) galactose-fed and high dose epalrestat $\left(50 \mathrm{mg} \cdot \mathrm{kg}^{-1} \cdot \mathrm{day}^{-1}\right)$-treated dogs. Control or galactose-fed dogs received normal dog chow (350 $\mathrm{g} \cdot \mathrm{day}^{-1}$ ) (Oriental Yest Co., Tokyo, Japan) containing 30\% non-nutrient fibre or $30 \%$ galactose, respectively. Epalrestat (Ono Pharmaceutical Co., Osaka, Japan) was given by gavage every day $1 \mathrm{~h}$ before feeding. The principles of laboratory animal care (NIH publication no. 85-23, revised 1995) were followed as well as the Animal Experimentation Guide of Nagoya University School of Medicine.

Morphological analysis. After 44 months of treatment, dogs were killed and the hearts and aortas were removed. Aortas were immediately frozen in liquid nitrogen and stored at $-80^{\circ} \mathrm{C}$ for assay of the galactitol content as described below. Hearts were preserved in $10 \%$ formaldehyde, followed by dehydration through a graded series of ethanol. The samples were embedded in paraffin and the cross-sections $(5 \mu \mathrm{m})$ at the level of bifurcation of left coronary arteries were stained with Elastica van Gieson for microscopic analysis using a computerized image analysis system $(\mathrm{C} \cdot$ imaging systems, Compix Inc., Mars, Pa., USA). Morphometric analysis was done on the intimal and medial layers of coronary arteries which had a diameter of $300-800 \mu \mathrm{m}$. Six measurements in each sample were carried out and the mean value was taken as the representative. The personnel who quantified the change were blinded to the treatment.

Assay of galactitol contents in aortas and erythrocytes. Blood obtained at 42 months was centrifuged at $1000 \times g$ for $10 \mathrm{~min}$ at $4{ }^{\circ} \mathrm{C}$ and the separated erythrocytes were washed twice with cold physiological saline and frozen at $-80^{\circ} \mathrm{C}$ until assay. Galactitol contents in aortas and erythrocytes were measured by a trimethylsilylether-based gas-liquid chromatographic method. The frozen aortas and erythrocytes were homogenized in $0.2 \mathrm{~N} \mathrm{ZnSO}_{4}$ containing $0.05 \mu \mathrm{mol} \alpha$-methyl-D-mannoside as an internal standard. The solution mixture was heated at $50{ }^{\circ} \mathrm{C}$ for $10 \mathrm{~min}$ and deproteinization was completed by the addition of $0.2 \mathrm{~N} \mathrm{Ba}(\mathrm{OH})_{2}$. After centrifugation at $1000 \times g$ for $10 \mathrm{~min}$ at $4{ }^{\circ} \mathrm{C}$, the supernatant was evaporated and dried to a residue, which was silylcated with $0.1 \mathrm{ml}$ of $N$-trimethylsilylimidazol (GL-Sciences, Tokyo, Japan) at $37^{\circ} \mathrm{C}$ for $1 \mathrm{~h}$. The trimetylsilyc ethers formed were then assayed with gas chromatograph (GC-17 A, Shimazu Co., Kyoto, Japan).

Biochemical assay. An aliquot of the serum obtained above was subjected to biochemical analysis. Glucose was determined by an enzymatic analysis (the glucose $\mathrm{C}$ test, Wako Pure Chemicals, Osaka, Japan). Total cholesterol concentrations were also measured by enzymatic methods (Determiner TC-S; Kyowa Medex, Tokyo, Japan). Erythrocyte $\mathrm{HbA}_{1 \mathrm{c}}$ values were measured by immunoassay (DCA-2000, Bayer-Sankyo Co., Tokyo, Japan).

Statistical analysis. Results are presented as means \pm SEM. Differences among experimental groups were detected by analysis of variance and the differences between groups was assessed by Scheffe's $S$ test. Significance was defined as a $p$ value less than 0.05 .

\section{Results}

Body weight and biochemical data. There were no significant differences in body weight or serum concentrations of glucose and total cholesterol between control and untreated galactose-fed dogs (Table 1). Erythrocyte $\mathrm{HbA}_{1 \mathrm{c}}$ values in untreated galactose-fed dogs were significantly higher than those in control dogs (Table 1). Treatment of galactose-fed dogs with either high or low dose epalrestat did not alter these variables.

Morphology of coronary arteries. Representative light photomicrographs of coronary arteries of control and galactose-fed dogs treated with or without high-dose epalrestat are shown in Fig.1. Untreated galactose-fed dogs showed remarkable intimal thickening compared with control dogs (Fig.1). This thickening was clearly diminished by treatment with highdose epalrestat (Fig.1). For the statistical analysis, the area of intimal layer was measured. Although there were no significant differences in the areas of intimal layer between each experimental condition, the areas of intimal layer in untreated galactose-fed dogs $\left(0.19 \pm 0.02 \mu \mathrm{m}^{2}\right)$ were larger than those in con- 

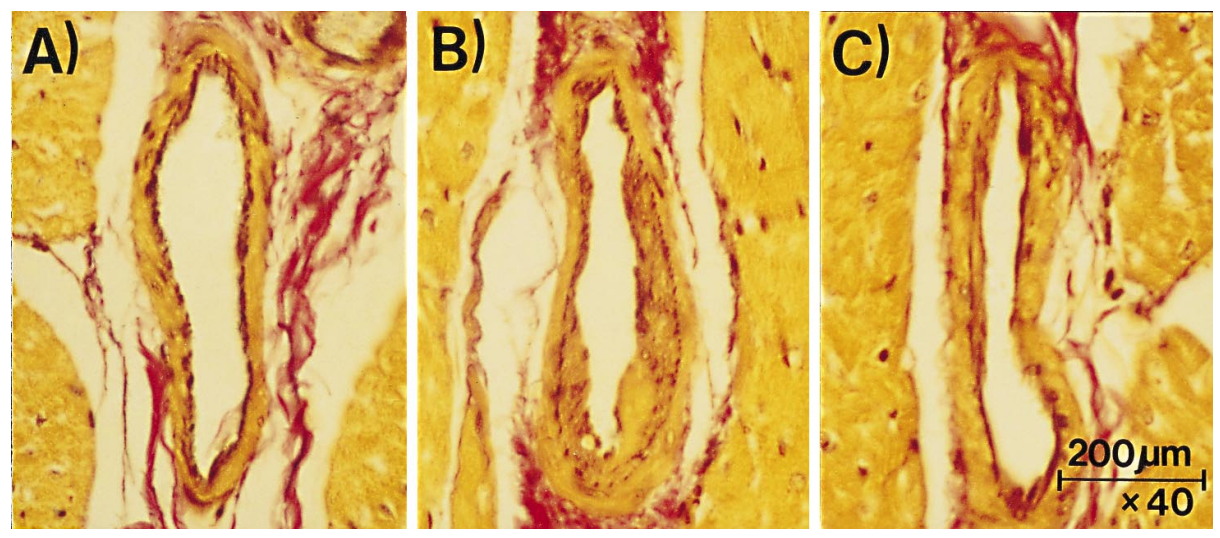

Fig.1A-C. Representative light photomicrographs of coronary arteries. A control dogs, $\mathbf{B}$ galactose-fed dogs, $\mathbf{C}$ galactose-fed dogs treated with high-dose $\left(50 \mathrm{mg} \cdot \mathrm{kg}^{-1}\right)$ epalrestat

trol dogs $(0.15 \pm 0.01)$ and treatment of galactose-fed dogs with low and high dose epalrestat decreased the areas of the intimal layer (low-dose: $0.16 \pm 0.02$, high-dose: $0.14 \pm 0.03$ ) (Fig. 2). The larger arteries have larger areas of intimal layer and there was a great variation in the diameters of the arteries used for measurement of the areas of intimal layer. This could result in no significant differences. Therefore, the areas of medial layer were also measured to compensate for the differences in the diameters of the arteries, and the intimal thickness was expressed as the ratio of the areas of intimal layer to those of medial layer (IA:MA) as reported previously [24]. The IA:MA in untreated galactose-fed dogs $(0.76 \pm 0.03$, $p<0.05)$ was significantly increased compared with that in control dogs $(0.39 \pm 0.03)$. Treatment of galactose-fed dogs with epalrestat significantly decreased the IA:MA in a dose-dependent fashion (low-dose: $0.56 \pm 0.03$, high-dose: $0.46 \pm 0.02, p<0.05$ ) (Fig. 2).

Galactitol content in aortas and erythrocytes. Galactitol was not detected in the aortas of control dogs. Untreated galactose-fed dogs had a remarkable accumulation of galactitol in their aortas $(0.68 \pm 0.12$ $\mathrm{nmol} \cdot \mathrm{mg}$ protein $^{-1}$ ), which was significantly diminished by treatment with epalrestat in a dose-depen- dent fashion (low-dose: $0.47 \pm 0.1$, high-dose: $0.22 \pm 0.03, p<0.05)$ (Fig. 3). The effects of galctose feeding and epalrestat on galactitol content in erythrocytes were similar to those in aortas (Fig.3).

\section{Discussion}

Our study showed that galactose feeding of beagle dogs for a long period caused intimal thickening in coronary arteries and galactitol accumulation in aortas and that these abnormalities were reduced by treatment with an aldose reductase inhibitor, epalrestat.

There are a few animal models of diabetes, such as mice [25], rabbits [26] and hamsters [27] which morphologically show atherosclerotic lesions. In addition, diabetic animals have hyperlipidaemia, which is one of the most important atherogenic factors. Therefore, it is impossible to investigate the role of hyperglycaemia itself in the development of atherosclerosis in diabetic animals. Previous studies have shown that the galactose-fed animal would be a useful model for investigating the pathogenesis of diabetic microangiopathy [14-20]. Pericyte ghost formation, microaneurysms and acellular capillaries in the retinas, which are characteristic features of diabetic retinopathy in humans, have been found in galactose-fed dogs [14]. Diabetes-like preproliferative abnormalities such as intraretinal microvascular abnormalities, occluded arterioles, preretinal and intravitreal haemorrhage and neovascularization in optic

Table 1. Body weight (BW), serum concentrations of glucose and total cholesterol (T- chol) and erythrocyte HbA $\mathrm{A}_{1 \mathrm{c}}$ values in control and galactose-fed dogs treated with or without epalrestat

\begin{tabular}{llllll}
\hline & $n$ & $\begin{array}{l}\mathrm{BW} \\
(\mathrm{kg})\end{array}$ & $\begin{array}{l}\text { Glucose } \\
\left(\mathrm{mmol} \cdot \mathrm{l}^{-1}\right)\end{array}$ & $\begin{array}{l}\mathrm{HbA}_{1 \mathrm{c}} \\
(\%)\end{array}$ & $\begin{array}{l}\mathrm{T}-\mathrm{chol} \\
\left(\mathrm{mmol} \cdot \mathrm{l}^{-1}\right)\end{array}$ \\
\hline Control & 4 & $9.6 \pm 0.3$ & $5.54 \pm 0.16$ & $3.5 \pm 0.1$ & $3.75 \pm 0.49$ \\
Galactose & 9 & $11.4 \pm 0.8$ & $5.51 \pm 0.11$ & $5.4 \pm 0.1^{\mathrm{a}}$ & $5.66 \pm 0.59$ \\
Galactose + L-ARI & 5 & $12.1 \pm 0.7$ & $5.81 \pm 0.09$ & $5.3 \pm 0.1^{\mathrm{a}}$ & $5.61 \pm 0.54$ \\
Galactose + H-ARI & 9 & $12.4 \pm 0.6$ & $5.62 \pm 0.14$ & $4.9 \pm 0.2^{\mathrm{a}}$ & $5.97 \pm 0.16$ \\
\hline
\end{tabular}

Values are means \pm SEM, L-ARI: low-dose $\left(20 \mathrm{mg} \cdot \mathrm{kg}^{-1}\right)$ epalrestat, H-ARI: high-dose $\left(50 \mathrm{mg} \cdot \mathrm{kg}^{-1}\right)$ epalrestat, ${ }^{\mathrm{a}} p<0.05 \mathrm{vs} \mathrm{con-}$ trol 

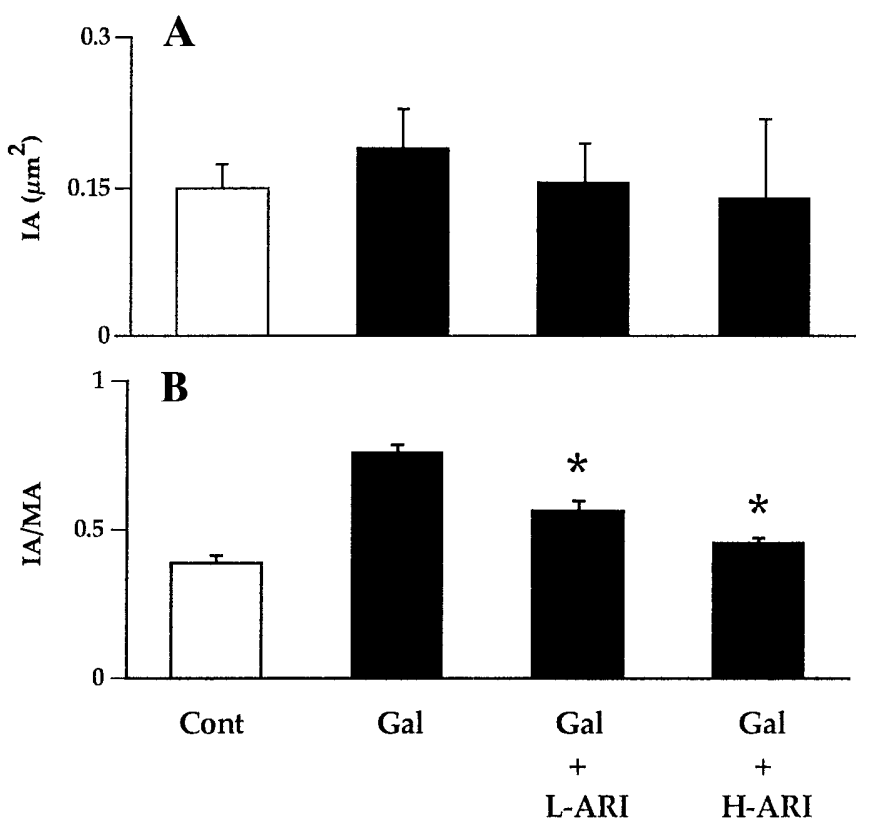

Fig. 2A, B. Morphometric analysis of the intimal thickening in coronary arteries of control and galactose-fed dogs treated with or without epalrestat. A areas of intimal layer (IA), $\mathbf{B}$ the ratio of the areas of intimal layer to those of medial layer (IA:MA). Cont: control, Gal: galactose, L-ARI: low-dose $\left(20 \mathrm{mg} \cdot \mathrm{kg}^{-1}\right)$ epalrestat, H-ARI: high-dose $\left(50 \mathrm{mg} \cdot \mathrm{kg}^{-1}\right)$ epalrestat. Values are means \pm SEM. $* p<0.05$ vs untreated galactose-fed dogs

discs have also been observed in galactosaemic dogs [15]. In addition, functional or morphological deficits similar to diabetic nephropathy or neuropathy have been detected in galactosaemic animals [16-20]. There are, however, few reports on macrovascular abnormalities in galactose-fed animal models, only biochemical or functional abnormalities of aortas consistent with those in diabetic animals have been reported $[8,21]$.

Galactose can be reduced to galactitol by aldose reductase, a late-limiting enzyme of the polyol pathway which converts glucose to sorbitol, but galactitol is not a substrate of sorbitol dehydrogenase which catalyses the conversion of sorbitol to fructose [13]. Therefore, galactosaemic animals have been used mainly to investigate the pathogenesis of diabetic microangiopathy from the view point of polyol pathway hyperactivity and the efficacy of aldose reductase inhibitors for preventing the development of diabetic microangiopathy. Several reports [28-30], in which the dose of an aldose reductase inhibitor, sorbinil, was relatively low, could not find beneficial effects of an aldose reductase inhibitor. Various studies have, however, reported preventive effects of aldose reductase inhibitors on the development of diabetes-like neuropathy [31], nephropathy [32], myopathy [31, $33]$ and retinopathy $[34,35]$ in galactose-fed animals. As for macrovascular abnormalities, it was reported that activation of the diacylglycerol (DAG)-PKC
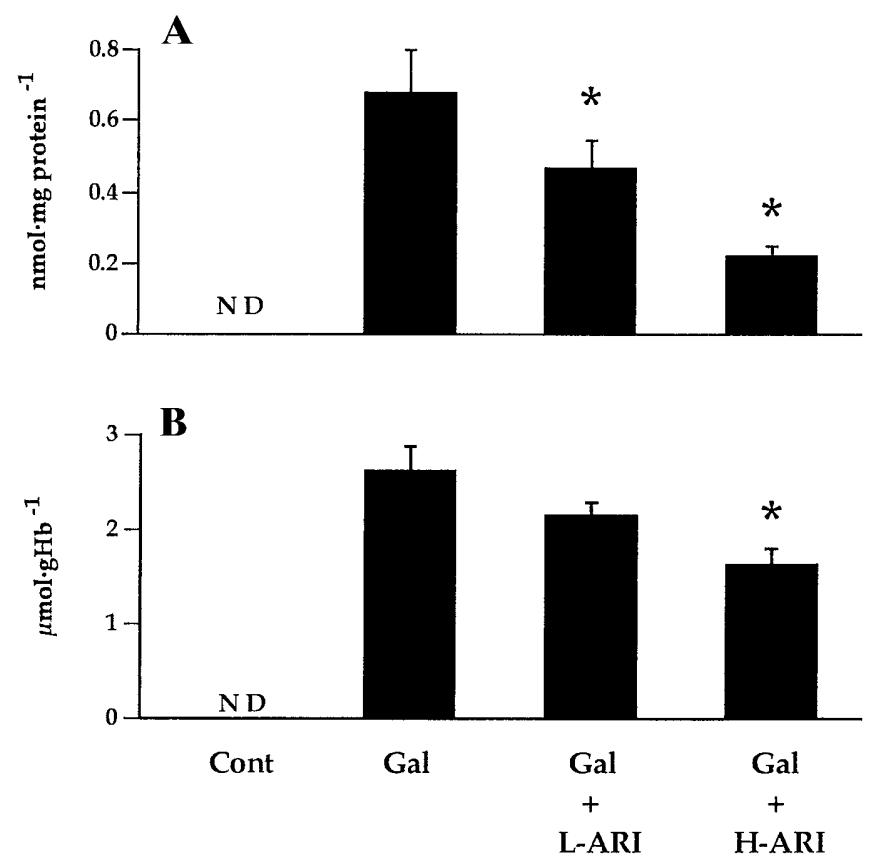

Fig. 3A, B. Galactitol contents in (A) aortas and (B) erythrocytes of control and galactose-fed dogs treated with or without epalrestat. Cont: control, Gal: galactose, L-ARI: low-dose $\left(20 \mathrm{mg} \cdot \mathrm{kg}^{-1}\right)$ epalrestat, H-ARI: high-dose $\left(50 \mathrm{mg} \cdot \mathrm{kg}^{-1}\right)$ epalrestat. ND: not detected. Values are means \pm SEM. $* p<0.05$ vs untreated galactose-fed dogs

pathway in galactosaemic aortas was not reduced by an aldose reductase inhibitor [8]. On the other hand, galactose-induced deficits in relaxation of aortas were prevented by aldose reductase inhibition [21]. Moreover, polyol accumulation and osmotic stress lead to compromised integrity of cell membranes [36], which facilitates non-receptor-mediated uptake of oxidized low-density lipoproteins which are implicated in intimal thickening [37, 38]. Our study also morphologically confirmed that the intimal thickening of coronary arteries of galactosaemic dogs can be prevented by an aldose reductase inhibitor. Although metabolic alterations due to hypergalactosaemia, apart from an accumulation of intracellular galactitol remain unclear, these observations suggest that aldose reductase inhibitor-sensitive metabolic alterations are responsible for the development of diabetes-like macroangiopathy as well as microangiopathy.

Initially, sorbitol accumulation which increases intracellular osmolality was considered to have a key role in the polyol pathway hyperactivity hypothesis. In recent studies, polyol pathway-related metabolic alterations such as myo-inositol depletion [39], increased oxidative stress [40], glycation [41] or altered PKC activity [5] rather than sorbitol accumulation itself have gained attention as the pathogenic factors of diabetic complications. Previous observations described above [31-35] and the results of this study verify the importance of intracellular sorbitol accu- 
mulation for the development of not only diabetic microangiopathy but also macroangiopathy.

Increases in oxidative stress, glycation [42] and DAG-PKC activity [43] have been implicated in the pathogenesis of diabetic macroangiopathy. Polyol pathway hyperactivity have been considered to be related to these metabolic deficits through an alteration of the redox state [44] including a decrease in NAD$\mathrm{PH}: \mathrm{NADP}^{+}$and an increase in NADH:NAD ${ }^{+}$. The latter causes an increase in DAG-PKC activity but not in galactose-induced polyol pathway hyperactivity itself as described above. An increase in NADH: $\mathrm{NAD}^{+}$has, however, been found in galactosaemic animals and was prevented by an aldose reductase inhibitor [45]. In addition, activation of the DAG-PKC pathway has been shown in the galactosaemic aorta [8]. Although the precise mechanism mediating an increase in NADH:NAD ${ }^{+}$and PKC activity in hypergalactosaemia remains unclear and PKC activity was not measured in this study, these observations and that the aldose reductase inhibition prevented the intimal thickening suggest that galactose-induced intimal thickening is mediated through polyol pathwayinduced activation of the DAG-PKC pathway.

A decrease in NADPH:NADP ${ }^{+}$can be observed not only in hyperglycaemia but also in hypergalactosaemia, resulting in an increase in oxidative stress through a reduction in glutathione. Increased oxygen radicals initiate lipid peroxidation, which, in turn, stimulate protein glycation [46, 47]. Furthermore, galactitol can be metabolized to galactitol-2-phosphate and galactitol-3-phosphate [48], which could be potent protein-glycating agents like fructose-3-phosphate [49]. Therefore, increased oxidative stress and the following acceleration of glycation in galactosaemia could be involved in the intimal thickening of coronary arteries. In fact, epalrestat prevented an increase in carboxymethyllysin, an advanced glycation end product, in aortas of galactosaemic dogs [50]. This could strongly support the close relation between increased polyol pathway activity and glycation in the development of diabetic macroangiopathy.

In summary, an intimal thickening of coronary arteries similar to that in diabetic macroangiopathy was observed in galactose-fed dogs concomitant with a remarkable accumulation of galactitol in their aortas and treatment with an aldose reductase inhibitor, epalrestat, significantly prevented these deficits. These observations suggest that polyol pathway hyperactivity is closely related to the development of diabetic macroangiopathy, which could be prevented by aldose reductase inhibition.

Acknowledgements. This work was supported in part by a Diabetes Research grant from the Ministry of Health and Welfare of Japan. The authors thank Mrs. H. Kitagawa and Miss S. Uno for technical assistance.

\section{References}

1. Laakso M, Lehto S (1997) Epidemiology of macrovascular disease in diabetes. Diabetes Rev 5: 294-315

2. Goldschmid MG, Barrett CE, Edelstein SL et al. (1994) Dyslipidemia and ischemic heart disease mortality among men and women with diabetes. Circulation 89: 991-997

3. The Diabetes Control and Complications Trial (DCCT) Research Group (1993) The effect of intensive treatment of diabetes on the development and progression of longterm complications in insulin-dependent diabetes mellitus. N Engl J Med 329: 977-986

4. The UK Prospective Diabetes Study (UKPDS) Group (1998) Effect of intensive blood-glucose control with metformin on complications in overweight patients with type 2 diabetes (UKPDS 34). Lancet 352: 854-865

5. Koya D, King GL (1998) Protein kinase C activation and the development of diabetic complications. Diabetes 47: 859-866

6. Greene DA, Sima AAF, Stevens MJ et al. (1992) Complications: neuropathy, pathogenetic considerations. Diabetes Care 15: 1902-1925

7. Hotta N (1995) New approaches for treatment in diabetes: aldose reductase inhibitors. Biomed Pharmacother 49: 232-243

8. Xia P, Inoguchi T, Kern TS et al. (1994) Characterization of the mechanism for the chronic activation of diacylglycerolprotein kinase $\mathrm{C}$ pathway in diabetes and hypergalactosemia. Diabetes 43: 1122-1129

9. Vlassara H (1996) Advanced glycation end-products and atherosclerosis. Ann Med 28: 419-426

10. Kashiwagi A, Asahina T, Ikebuchi M et al. (1994) Abnormal glutathione metabolism and increased cytotoxicity caused by $\mathrm{H} 2 \mathrm{O} 2$ in human umbilical vein endothelial cells cultured in high glucose medium. Diabetologia 37: 264-269

11. Sakakibara F, Hotta N, Koh N, Sakamoto N (1993) Effects of high glucose concentrations and epalrestat on sorbitol and myo-inositol metabolism in cultured rabbit aortic smooth muscle cells. Diabetes 42: 1594-1600

12. Yasunari K, Kohno M, Kano H et al. (1995) Aldose reductase inhibitor prevents hyperproliferation and hypertrophy of cultured rat vascular smooth muscle cells induced by high glucose. Arterioscler Thromb Vasc Biol 15: 2207-2212

13. Dvornik D (1987) Hyperglycemia in pathogenesis of diabetic complications. In: D Porte (ed) Aldose Reductase Inhibition. An Approch to Prevention of Diabetic Complications. McGraw-Hill, New York, pp 69-152

14. Engerman RL, Kern TS (1984) Experimental galactosemia produces diabetic-like retinopathy. Diabetes 33: 97-100

15. Takahashi Y, Wyman M, Ferris F III, Kador PF (1992) Diabetes like preproliferative retinal changes in galactose-fed dogs. Arch Ophthalmol 110: 1295-1302

16. Kern TS, Engerman RL (1987) Kidney morphology in experimental hyperglycemia. Diabetes 36: 244-249

17. Engerman RL, Kern TS (1989) Hyperglycemia and development of glomerular pathology: diabetes compared with galactosemia. Kidney Int 36: 41-45

18. Calcutt NA, Tomlinson DR, Biswas S (1990) Coexistence of nerve conduction deficit with increased $\mathrm{Na}(+)-\mathrm{K}(+)$ ATPase activity in galactose-fed mice. Implications for polyol pathway and diabetic neuropathy. Diabetes 39: 663-666

19. Kamijo M, Basso M, Cherian PV, Hohman TC, Sima AA (1994) Galactosemia produces ARI-preventable nodal changes similar to those of diabetic neuropathy. Diabetes Res Clin Pract 25: 117-129 
20. Tilton RG, Pugliese G, LaRose LS et al. (1991) Discordant effects of the aldose reductase inhibitor, sorbinil, on vascular structure and function in chronically diabetic and galactosemic rats. J Diabetes Complications 5: 230-237

21. Cameron NE, Cotter MA (1994) Contraction and relaxation of aortas from galactosaemic rats and the effects of aldose reductase inhibition. Eur J Pharmacol 243: 47-53

22. Terashima H, Hama K, Yamamoto R et al. (1984) Effects of a new aldose reductase inhibitor on various tissues in vitro. J Pharmacol Exp Ther 229: 226-230

23. Hotta N, Kakuta H, Fukasawa H et al. (1985) Effects of a fructose-rich diet and the aldose reductase inhibitor, ONO-2235, on the development of diabetic neuropathy in streptozotocin-treated rats. Diabetologia 28: 176-180

24. Andersen HO, Madsen G, Nordestgaard BG et al. (1994) Cyclosporin suppresses transplant arteriosclerosis in the aorta-allografted, cholesterol-clamped rabbit. Suppression preceded by decrease in arterial lipoprotein permeability. Arterioscler Thromb 14: 944-950

25. Kunjathoor VV, Wilson DL, LeBoeuf RC (1996) Increased atherosclerosis in streptozotocin-induced diabetic mice. J Clin Invest 97: 1767-1773

26. Chen YL, Huang HC, Weng YI, Yu YJ, Lee YT (1994) Morphological evidence for the antiatherogenic effect of scoparone in hyperlipidaemic diabetic rabbits. Cardiovasc Res 28: 1679-1685

27. Sima A, Popov D, Starodub O et al. (1997) Pathobiology of the heart in experimental diabetes: immunolocalization of lipoproteins, immunoglobulin $\mathrm{G}$, and advanced glycation endproducts proteins in diabetic and/or hyperlipidemic hamster. Lab Invest 77: 3-18

28. Engerman RL, Kern TS (1993) Aldose reductase inhibition fails to prevent retinopathy in diabetic and galactosemic dogs. Diabetes 42: 820-825

29. Engerman RL, Kern TS, Larson ME (1994) Nerve conduction and aldose reductase inhibition during 5 years of diabetes or galactosaemia in dogs. Diabetologia 37: 141-144

30. Frank RN, Zhang NL (1990) Sorbinil does not prevent galactose-induced glomerular capillary basement membrane thickening in the rat. Diabetologia 33: 515-521

31. Cameron NE, Cotter MA, Robertso S, Cox D (1992) Muscle and nerve dysfunction in rats with experimental galactosaemia. Exp Physiol 77: 89-108

32. Forster HG, Wee PM, Hohman TC, Epstein M (1996) Impairment of afferent arteriolar myogenic responsiveness in the galactose-fed rat is prevented by tolrestat. Diabetologia 39: 907-914

33. Cotter MA, Cameron NE, Robertson S (1992) Polyol pathway-mediated changes in cardiac muscle contractile properties: studies in streptozotocin-diabetic and galactose-fed rats. Exp Physiol 77: 829-838

34. Akagi Y, Kador PF (1990) Effect of aldose reductase inhibitors on the progression of retinopathy in galactose-fed dogs. Exp Eye Res 50: 635-639

35. Kador PF, Akagi Y, Terubayashi H, Wyman M, Kinioshita JH (1988) Prevention of pericyte ghost formation in retinal capillaries of galactose-fed dogs by aldose reductase inhibitors. Arch Ophthalmol 106: 1099-1102
36. Burg MB, Kador PF (1988) Sorbitol, osmoregulation, and the complications of diabetes. J Clin Invest 81: 635-640

37. Matthys KE, Van Hove CE, Kockx MM et al. (1998) Exposure to oxidized low-density lipoprotein in vivo enhances intimal thickening and selectively impairs endothelium-dependent dilation in the rabbit. Cardiovasc Res 37: 239-246

38. Matthys KE, Van Hove CE, Kockx MM et al. (1997) Local application of LDL promotes intimal thickening in the collared carotid artery of the rabbit. Arterioscler Thromb Vasc Biol 17: 2423-2429

39. Greene DA, Lattimer SA, Sima AAF (1987) Sorbitol, phosphoinositides, and sodium-potassium-ATPase in the pathogenesis of diabetic complications. N Engl J Med 316: 599-606

40. Giugliano D, Ceriello A, Paolisso G (1996) Oxidative stress and diabetic vascular complications. Diabetes Care 19: 257-267

41. Brownlee M (1995) Advanced protein glycosylation in diabetes and aging. Annu Rev Med 46: 223-234

42. Taniguchi N, Kaneto H, Asahi M et al. (1996) Involvement of glycation and oxidative stress in diabetic macroangiopathy. Diabetes 45[Suppl 3]:S81-S83

43. Inoguchi T, Battan R, Handler E et al. (1992) Preferential elevation of protein kinase $\mathrm{C}$ isoform beta II and diacylglycerol levels in the aorta and heart of diabetic rats: differential reversibility to glycemic control by islet cell transplantation. Proc Natl Acad Sci USA 89: 11059-11063

44. Williamson JR, Chang K, Frangos et al. (1993) Hyperglycemic pseudohypoxia and diabetic complications. Diabetes 42: 801-813

45. Obrosova I, Faller A, Burgan J et al. (1997) Glycolytic pathway, redox state of NAD(P)-couples and energy metabolism in lens in galactose-fed rats: effect of an aldose reductase inhibitor. Curr Eye Res 16: 34-43

46. Nagaraj RH, Prabhakaram M, Ortwerth BJ, Monnier VM (1994) Suppression of pentosidine formation in galactosemic rat lens by an inhibitor of aldose reductase. Diabetes 43: 580-586

47. Jain SK, Palmer M (1997) The effect of oxygen radicals metabolites and vitamin $\mathrm{E}$ on glycosylation of proteins. Free Radic Biol Med 22: 593-596

48. Kappler F, Su B, Szwergold BS, Randall WC, Brown TR (1995) Identification of galactitol 2-phosphate and galactitol 3-phosphate in the lens of galactose-fed rats. Metabolism 44: 1527-1531

49. Lal S, Szwergold BS, Taylor AH et al. (1995) Metabolism of fructose-3-phosphate in the diabetic rat lens. Arch Biochem Biophys 318: 191-199

50. Hamada Y, Kasuya Y, Nakamura J et al. (1998) Effect of aldose reductase inhibitor on carboxymethyllysinc levels in aorta from galactose-fed dogs and in erythrocytes from diabetic patients. Diabetologia 41[Suppl 1]:A301 (Abstract) 